\title{
Effects of Glyphosate-Based Herbicide Sub-Lethal Concentrations on Fish Feeding Behavior
}

\author{
Percilia Cardoso Giaquinto ${ }^{1}$ (1) $\cdot$ Marina Borges de Sá ${ }^{1} \cdot$ Vanessa Seiko Sugihara $^{1} \cdot$ \\ Bruno Bastos Gonçalves ${ }^{1} \cdot$ Helton Carlos Delício ${ }^{1} \cdot$ Assaf Barki $^{2}$
}

Received: 11 July 2016 / Accepted: 25 January 2017 / Published online: 10 February 2017

(C) Springer Science+Business Media New York 2017

\begin{abstract}
Glyphosate-based herbicides are widely used in agricultural systems. Although the target organism are particularly plant organisms, there are numerous studies showing adverse effects in aquatic animals, such as inhibition of acetyl cholinesterase, effects on kidney, liver, and gill and stressors effects. This study analyzed the effects of commercial formulation of glyphosate on feeding behavior in Pacu (Piaractus mesopotamicus). Fish were exposed to three glyphosate concentrations $(0.2,0.6$, and $1.8 \mathrm{ppm})$ for 15 days. At concentrations of 0.2 and $0.6 \mathrm{ppm}$, food intake decreased on day 13 and then returned to normal on day 15 . At the highest glyphosate-based herbicide concentration, $1.8 \mathrm{ppm}$, food consumption decreased dramatically and did not recover on day 15 . This study showed that glyphosatebased herbicide at sub-lethal concentrations can affect feed intake in pacu and consequently inhibits its growth.
\end{abstract}

Keywords Roundup - Herbicide - Feeding behavior . Piaractus mesopotamicus

Glyphosate is a potent organophosphorous substance, widely used as an herbicide in agricultural production to control plant pests such as weeds (Timmermann et al. 2003). Glyphosate is systemic herbicide acting in plant organisms by inhibiting the synthesis of some essential

Percilia Cardoso Giaquinto

percilia@ibb.unesp.br

1 Physiology Department, Institute of Biosciences, State University of Sao Paulo - UNESP, Botucatu, Sao Paulo, Brazil

2 Agricultural Research Organization, Institute of Animal Science, Bet Dagan, Israel amino acids (as tyrosine, tryptophan and phenylalanine), thus leading to death of growing plants (Cole 1985; Franz et al. 1997). However, concerns about the exposure of animals and human to this substance persist, as several studies showed negative effects on animals (Giesyet al. 2000), such as inhibiting acetyl cholinesterase, effects on kidney, liver, and gill (in aquatic animals) and various stressors effects (Cattaneo et al. 2011; Glusczak et al. 2006; MenéndezHelman et al. 2012; Lajmanovich et al. 2011; Langiano and Martinez 2008; Modesto and Martinez 2010; Salbegoet al. 2010; Sandrini et al. 2013).

Herbicides can reach aquatic environments via agricultural runoff and leaching processes, as well as by direct applications to control invasive aquatic weeds (Annett et al. 2014). Once in the aquatic ecosystems, herbicides may reduce environmental quality and influence essential ecosystem webs by reducing species diversity and community structures, modifying food chains, changing patterns of energy flow, nutrient cycling and changing the stability and resilience of ecosystems.

The laws in USA, European countries and Brazil allow the use of this herbicide and determine maximum concentrations in water bodies ( $7 \mathrm{ppm})$ in the United States, $0.001 \mathrm{ppm}$ in European countries and $0.65 \mathrm{ppm}$ glyphosate in Brazil (Amarante-Junior and Santos 2002). Despite establishing limits in the application of the herbicide and maximum concentration in water bodies, the increased and indiscriminate use of these products results in contamination of aquatic environments with concentrations well above those permitted by law (Annett et al. 2014).

Fish growth is a consequence of a cascade of behavioral and physiological events, and it is assumed that the stress have a negative impact on organisms due to prolonged activation of the hypothalamic-pituitary-interrenal (HPI) axis (Bernier et al. 2004). Environmental, social and physical 
stressors, mediated by components of the HPI axis, can affect fish growth by inhibiting food intake, absorption or conversion efficiency of food into body (Benoit et al. 2000; Bernier et al. 2004; Heinrichs and Richard 1999; Smagin et al. 1998).

Despite the identified harmful physiological effects of exposure to glyphosate, especially at high concentrations, there has been no attempt to evaluate the long-term impact of low concentrations of glyphosate in the water, especially concerning possible effects on key behaviors for survival. Thus, the objective of this study was to determine the effect of glyphosate-based herbicide on fish feeding behavior.

\section{Materials and Methods}

Pacu (Piaractus mesopotamicus) was chosen as animal model, since it is a native species in Brazil, with a high ecological and economic relevance. Fish were obtained from an aquaculture farm and acclimatized in a vivarium for a month before the experiments. The fish (length $7.35 \pm 0.35 \mathrm{~cm}$ and weight $12.53 \mathrm{~g} \pm 1.64$ ) were maintained in $300 \mathrm{~L}$ tanks with a constant aeration, at a density of 1 fish/L. Water temperature ranged between 24 and $26^{\circ} \mathrm{C}, \mathrm{pH}$ averaged 7, ammonia was maintained below $0.04 \mathrm{mg} / \mathrm{L}$ and a $12 \mathrm{~h}$ light phase from 06:00 am to 06:00 pm was applied. The fish were fed once daily (until satiety) with tropical fish food (36\% of protein). Ethics committee of animal use (CEUA) of UNESP, Botucatu, SP, Brazil (protocol number 484), previously approved all procedures.

The commercial glyphosate formulation used was Isopropylamine salt of N-phosphonomethyl glycine $480 \mathrm{~g} / \mathrm{L}$, 3-iodo 2-propynyl butyl carbamate at $0.017 \%$. We calculate the lethal concentration (LC50) to establish sublethal concentrations for this study. For that, we randomly distributed 50 juvenile pacu in five groups of $10 \mathrm{fish}$, at different glyphosate concentrations $(0,1,10,50$ and 100 ppm). There was no difference in length $(p=0.69)$ and weight ( $p=0.78$ ) between groups. The LC50 for $48 \mathrm{~h}$ was calculated through trimmed Spearman-Karber method (Hamilton et al. 1977) with TSK package on R software. The LC50 found was $22.36 \mathrm{ppm}$. The concentrations used in this work were sub-lethal; 0.2 (0.9\% of LC50), $0.6(2.68 \%$ of LC50) and $1.8 \mathrm{ppm}$ (8\% of LC50).

The experimental design consisted of measuring the latency to feed and the amount of food ingestion before exposure and measuring it again on 10, 11, 13,14 and 15 days after exposure to different sub-lethal concentrations of glyphosate-based herbicide (0.2, 0.6 and $1.8 \mathrm{ppm})$.

We placed 18 fish in $20 \mathrm{~L}$ glass aquariums individually and allowed them to acclimate for $48 \mathrm{~h}$ before the beginning of experiments. At the first day, prior to adding the glyphosate-based herbicide, we gave 10 fish-feed pellets for each fish and measured the latency to feed and number of pellets ingested after $20 \mathrm{~min}$. Twenty-four hours after that we added the glyphosate-based herbicide to the aquarium water at the concentrations $0.2,0.6$ and $1.8 \mathrm{ppm}$. To assess the rate of glyphosate degradation in the water at initial concentrations of $0.2,0.6$ and $1.8 \mathrm{ppm}$, glyphosate concentrations were monitored during 8 days, according to Hidalgo et al. (2004). The method showed a limit of detection (LD) of glyphosate in water of $0.05 \mu \mathrm{g} / \mathrm{L}$, a limit of quantification (LQ) of $0.15 \mu \mathrm{g} / \mathrm{L}$, a maximum detectable concentration of $5 \mu \mathrm{g} / \mathrm{L}$ and a mean recovery rate of $101 \%$. For quantification, a four-point calibration curve $(0.075,0.2,0.75$ and $5 \mu \mathrm{g} / \mathrm{L})$ was constructed with two replicates each. An analytical quality control solution $(0.5 \mu \mathrm{g} / \mathrm{L})$ was also used. All samples were analyzed for duplicate and those with glyphosate concentrations above the calibration curve were diluted until concentration could be reliably estimated. During 8 days, Glyphosate concentrations decreased by $3.95 \%$, $3.18 \%$ and $4.96 \%$, respectively (Table 1 ), with a clear linear trend (linear regression, $\mathrm{R}^{2}=0.89,0.97$ and 0.99, respectively). Accordingly, we could conservatively estimate that by day 15 (the last experimental day) glyphosate decrease would not exceed $10 \%$ of the initial concentration in all treatments. Thus it seemed reasonable to assume that possible effects of glyphosate and differential treatment effects would be maintained throughout the experimental period and would not be biased by differential degradation rates.

For the following 15 days, the fish were daily fed as in the first day. On each of days 10, 11, 13, 14 and 15 we measured the latency to feed and number of pellets ingested 20 min after feeding.

For assessment of the effect of glyphosate-based herbicide on feeding behavior we compared the latency to feed and number of eaten pellets among the different concentration treatments using repeated measures ANOVA, with day as random effect. Tukey-Kramer HSD test was used for aposteriori analysis. Normality and homoscedasticity were verified through Kolmogorov-Smirnovand Levene tests, respectively. To meet ANOVA assumptions, data of the number of ingested pellets was $\log (\mathrm{x}+1)$ transformed. Significance level was set at $\alpha=0.05$.

Table 1 Glyphosate concentrations (ppm) in the aquaria water during 8 days and percentage of initial concentration (in parentheses)

\begin{tabular}{lccc}
\hline Day & \multicolumn{4}{l}{ Glyphosate concentration (ppm) } \\
\hline 1 & $0.2(100 \%)$ & $0.6(100 \%)$ & $1.8(100 \%)$ \\
2 & $0.197(98.62 \%)$ & $0.594(99.02 \%)$ & $1.780(98.87 \%)$ \\
4 & $0.197(98.66 \%)$ & $0.590(98.32 \%)$ & $1.756(97.54 \%)$ \\
6 & $0.196(97.78 \%)$ & $0.585(97.55 \%)$ & $1.733(96.27 \%)$ \\
8 & $0.192(96.05 \%)$ & $0.581(96.82 \%)$ & $1.711(95.04 \%)$ \\
\hline
\end{tabular}




\section{Results and Discussion}

The exposure of P. mesopotamicus to $1.8 \mathrm{ppm}$ of glyphosate-based herbicide decreased the number of pellets ingested by fish $(p=0.00001$; Fig. 1), as compared to control (before glyphosate-based herbicide exposure). At $1.8 \mathrm{ppm}$, the pellets consumption was low since day 10 and kept lower until the last day of the experiment (15th day) (Fig. 1). However, the exposure of $0.2 \mathrm{ppm}$ led to lower ingestion of pellets just on day $13(p=0.0003)$ and $14(p=0.038)$, going back to a normal consumption at 15 days of exposure $(p=0.73)$. A similar pattern was observed at $0.6 \mathrm{ppm}$ concentration with lower ingestion on day 13 $(p=0.01)$, but the recovery was on day 14 . Glyphosatebased herbicide exposure also significantly increased the latency to feed relative to 'before' at $1.8 \mathrm{ppm}$, but didn't increase significantly at 0.6 and $0.2 \mathrm{ppm}$ (Fig. 2).

These negative effects on the fish feeding behavior are perturbing in light of the fact that the highest tested concentration $(1.8 \mathrm{ppm})$ can also be found in the field (Thompson et al. 2004). This effect can be intensified, considering that fishes do not seem to avoid glyphosate and there is no scientific consensus that they avoid commercial formulations as used in this study (Tierney et al. 2010). Kasumyan (2001) has reviewed effects of pollutants on feeding behavior of fishes. Here we show for the first time the effects of long-term exposure (10-15 days) to glyphosate-based herbicides on feeding behavior of fish, specifically on P. mesopotamicus, an important species from the economic and conservation point of view.
Fig. 1 Number of pellets ingested by pacu (Piaractus mesopotamicus) before and on days $10,11,13,14$ and 15 after exposure to different concentrations of glyphosate-based herbicide. *Indicates statistical significance of each time-point from before exposure time. Symbols (circle, square and triangle) represent the mean of each treatment and bars represent the standard error of the mean

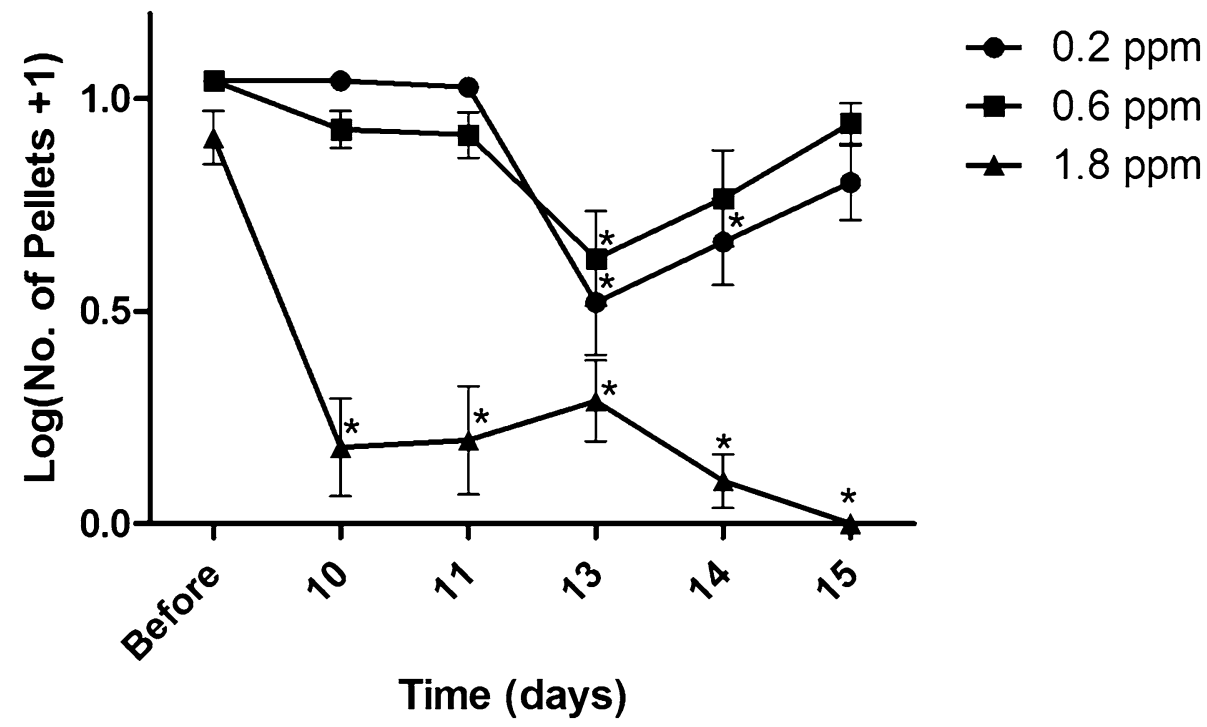

Fig. 2 Latency in seconds of Pacu (Piaractus mesopotamicus) to start feeding before exposure and days 10,11, 13, 14 and 15 after exposure to different concentrations of glyphosate-based herbicide. *Indicates statistical significance of each time-point from before exposure time. Symbols (circle, square and triangle) represent the mean of each treatment and bars represent the standard error of the mean

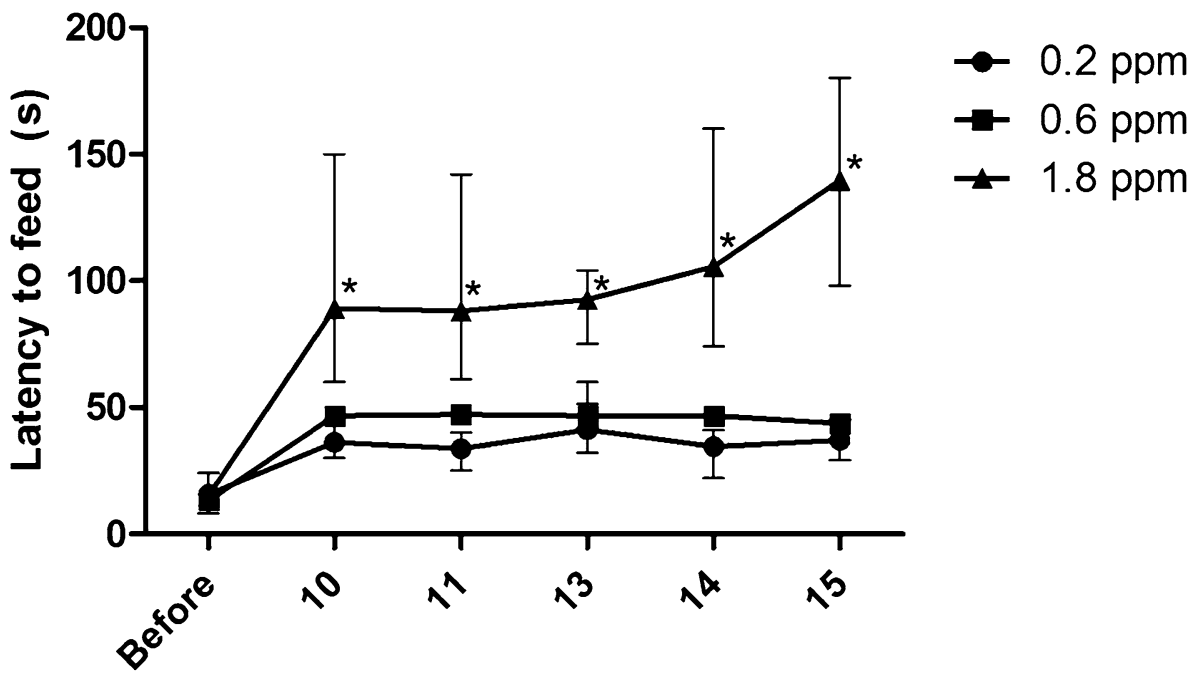

Time (days) 
There are some explanations for why glyphosate-based herbicides might lead to reduced food intake and higher latency to feed. One of them is that the presence of the herbicide in the water can modify the taste of food, leading to reduced attractiveness of food to fishes. Another explanation is disruption of the olfactory system. Tierneyet al. (2006) showed that acute exposure of Onchorynchus kisutch to $1 \mathrm{ppm}$ or higher of glyphosate (just the active substance) leads to reduced Electro-Olfactogramactivity when it detects Lserine in the environment. Their argument is that glyphosate resemble the aminoacid glycine and there is some overlapping for the same active site for Lserine substance. As a result, fish cannot detect Lserine and it does not respond to its presence. However, when the active site is available again (during recovering time), the fish restore their initial capability to detect Lserine.

For commercial formulations, as used in this study, Tierneyet al. (2007a) showed that Roundup ${ }^{\circledR}$ is considerable more toxic than the active ingredient (glyphosate only), probably due to negative effects of surfactants on the olfactory system (Sutterlin and Sutterlin 1971).

Another possible cause for olfactory system disruption is through Acetyl cholinesterase (ACHE) impairment. It is well known that glyphosate-based herbicides leads to disruption of ACHE activity, resulting in malfunction of neuro-transmission (Glusczak et al. 2006; MenéndezHelman et al. 2012; Modesto and Martinez 2010; Salbego et al. 2010; Sandrini et al. 2013). Considering that production of mucous on olfactory epithelium is up regulated by the secretion of ACHE, the lack of this enzyme can result in over-production of mucous, increasing the thickness of mucous layer and the distance between odoriferous molecules and active sites of neuroreceptors, leading to lack of olfactory sensitivity (Inglis et al. 1997; Jarrard et al. 2004; Tierney et al. 2007b).

One factor that we should consider is the stress response of the fish. Experimental manipulations, new environment and social isolation usually lead to stress response in fish, manifested in increased cortisol levels. However, sub-lethal concentrations of agrichemicals were reported to decrease plasma cortisol levels and disrupt stress response in fish (Cerciato et al. 2008). It is well known that cortisol leads to increased food intake (Bernier et al. 2004). Thus, we suggest that the reducing effect of glyphosate on food ingestion was mediated by cortisol; the manipulation at the beginning of the experiment could have caused some stress response on those fish, resulting in cortisol release and stimulating food intake. As we submitted them to glyphosate treatments, depending on concentration (as in Bernier et al. 2004; Cerciato et al. 2008), cortisol release was disrupted, resulting in reduced feed ingestion in the highest tested concentration (1.8 ppm). Glyphosate also have impacts on fish growth that can be related to food intake or food conversion efficiency (Bernier et al. 2004; Salbego et al. 2010).

In an economic perspective, $P$. mesopotamicus is highly appreciated for human consumption and aquaculture. Glyphosate-based herbicides, especially Roundup ${ }^{\circledR}$, is broadly used in farms for weed control and can reach (through runoff and leaching) aquaculture ponds and reduce algal food resource in the water. There by, it might reduce the growth rate of herbivore fishes in these aquaculture systems, resulting in losses to fish growers.

In a conservation perspective, considering that concentrations used in this study is compatible with reality (from 0.00001 to $1.9 \mathrm{ppm}$; Annett et al. 2014), and considering that that fishes cannot avoid and possibly do not have an avoidance behavior with glyphosate, they can be directly affected by glyphosate-based herbicides that impose reduced consumption of food. In common situations where natural food is scarce, this can be very dangerous, because animals must get all food that they need to survive in unfavorable times and places.

There are regulations for using glyphosate-based herbicides and governments around the world determine limits to glyphosate concentrations in natural water bodies. EPA (USA) established 7 ppm, while Brazilian government stated 0.65 ppm (CONAMA 357) and European governments only $0.001 \mathrm{ppm}$ (Amarante-Junior and Santos 2002). According to our results, EPA and Brazilian government need to review their laws, looking not just on survival of native species in natural environments, but also on their well-being.

In conclusion, the present study shows for the first time that long-term exposure to sub-lethal concentrations of glyphosate-based herbicides can decrease feeding activity and appetite in P. mesopotamicus, a native species in Brazil with great ecological and economical relevance. Such interference obviously has deleterious fitness consequences for individual fish, and in the long run it may adversely affect whole fish populations. This fact has a great impact in terms of conservation, considering that glyphosate-based herbicides are widespread at sublethal concentration in natural environments. It is therefore advisable for scientists to look for seemingly subtle effects such as those related to feeding behavior without any evident damage, and furthermore, for decision maker to consider revision of permitted herbicides levels in the aquatic environment.

Acknowledgements The funding was provided by Fundação de Amparo à Pesquisa do Estado de São Paulo (Grant No. 2013/02430-2). 


\section{References}

Amarante-Junior OP, Santos TCR (2002) Glifosato: propriedades, toxicidade, usos e legislação. Quimica nova 25(4):593-598

Annett R, Habibi HR, Hontela A (2014) Impact of glyphosate and glyphosate-based herbicides on the freshwater environment. J Appl Toxicol 34:458-479

Benoit SC, Thiele TE, Heinrichs SC, Rushing PA, Blake KA, Steeley RJ (2000) Comparison of central administration of corticotropinreleasing hormone and urocortin on food intake, conditioned taste aversion, and c-Fos expression. Peptides 21:345-351

Bernier NJ, Bedard N, Peter RE (2004) Effects of cortisol on food intake, growth, and forebrain neuropeptide $\mathrm{Y}$ and corticotropinreleasing factor gene expression in goldfish. Gen Comp Endocr 135:230-240

Cattaneo R, Clasen B, Loro VL, De Menezes CC, Pretto A, Baldisserotto B, Santi A, De Avila LA (2011) Toxicological responses of Cyprinus carpio exposed to a commercial formulation containing glyphosate. Bull Environ Contam Toxicol 87(6):597-602

Cerciato L, Machado-Neto JG, Fagundes M, Kreutz LC, Quevedo RM, Finco J, Rosa JGS, Koakoski G, Centenaro L, Pottker E, AnzilieroD, Barcellos LJG (2008) Cortisol response to acute stress in jundiá Rhamdia quelen acutely exposed to sub-lethal concentrations of agrichemicals. Comp Biochem Physiol Part C 148:281-286

Cole DJ (1985) Mode of action of glyphosate-a literature analysis. In: Grossbard E, Atkinson D (eds) The herbicide glyphosate. Butterworths, London, pp 49-54

Franz JE, Mao MK, Sikorski JA (1997) Glyphosate: a unique global herbicide. ACS monograph 189. American Chemical Society, Washington

Giesy JP, Dobson S, Solomon KR (2000) Ecotoxicological risk assessment for Roundup ${ }^{\circledR}$ herbicide. Rev Environ Contam Toxicol 167:35-120

Glusczak L, Miron DDS, Crestani M, Da Fonseca MB, Pedron FDA, Duarte MF, Vieira VUP (2006) Effect of glyphosate herbicide on acetylcholinesterase activity and metabolic and hematological parameters in Piava (Leporinus obtusidens). Ecotoxicol Environ Saf 65:237-241

Hamilton MA, Russo RC, Thurston RB (1977) Trimmed SpermanKarber method for estimating median lethal concentrations in toxicity bioassays. Environ Sci Technol 11(7):714-719

Heinrichs SC, Richard D (1999) The role of corticotropin-releasing factor and urocortin in the modulation of ingestive behavior. Neuropeptides 33:350-359

Hidalgo C, Rios C, Hidalgo M, Salvado V, Sancho JV, Hernandez F (2004) Improved coupled-columm liquid chromatographic method for the determination of glyphosate and aminomethylphosphonic acid residues in environmental waters. J Chromatogr 1035(A): 153-157

Inglis SK, Corboz MR, Taylor AE, Ballard ST (1997) In situ visualization of bronchial submucosal glands and their secretory response to acetylcholine. Am J Physiol Lung Cell Mol Physiol 272(2):203-210

Jarrard HE, Delaney KR, Kennedy CJ (2004) Impacts of carbamate pesticides on olfactory neurophysiology and cholinesterase activity in coho salmon (Oncorhynchus kisutch). Aquat Toxicol 69:133-148

Kasumyan AO (2001) Effects of chemical pollutantes on foraging behavior and sensitivity of fish to food stimuli. J Ichthyol 41(1):76-87

Lajmanovich RC, Attademo AM, Peltzer PM, Junges CM, Cabagna MC (2011) Toxicity of four herbicide formulations with glyphosate on Rhinellaarenarum (Anura: Bufonidae) tadpoles: B-esterases and glutathione s-transferase inhibitors. Arch Environ Contam Toxicol 60:681-689

Langiano VC, Martinez CBR (2008) Toxicity and effects of a glyphosate-based herbicide on the neotropical fish Prochilodus lineatus. Comp Biochem Physiol 147:222-231

Menéndez-Helman RJ, FerreyroaGV, Afonso MSA (2012) Glyphosate as an acetylcholinesterase inhibitor in Cnesterodondecem maculatus. B Environ Contam Toxicol 88:6-9

Modesto KA, Martinez CBR (2010) Effects of Roundup Transorb on fish: hematology, antioxidant defenses and acetylcholinesterase activity. Chemosphere 81:781-787

Salbego J, Pretto A, Gioda CR, De Menezes CC, Lazzari R, Neto JR, Baldisserotto B, Loro VL (2010) Herbicide formulation with glyphosate affects growth, acetyl cholinesterase activity, and metabolic and hematological parameters in Piava (Leporinus obtusidens). Arch Environ Contam Toxicol 58(3):740-745

Sandrini JZ, Rola RC, Lopes FM, Buffon HF, Freitas MM, Martins CMG, Rosa CE (2013) Effects of glyphosate on cholinesterase activity of the mussel Perna perna and the fish Daniorerio and Jenynsia multidentata: In vitro studies. Aquat Toxicol 130-131:171-173

Smagin GN, Howell LA, Ryan DH, De Souza EB, Harris RBS (1998) The role of CRF2 receptors in corticotropin-releasing factor- and urocortin induced anorexia. Neuroreport 9:1601-1606

Sutterlin AM, Sutterlin N (1971) Electrical responses of the olfactory epithelium of Atlantic salmon (Salmosalar). J Fish Res Board Can 28:565-572

Thompson DG, Wojtaszek BF, Staznik B, Chartrand DT, Stephenson GR (2004) Chemical and biomonitoring to assess potential acute effects of Vision ${ }^{\circledR}$ herbicide on native amphibian larvae in forest wetlands. Environ Toxicol Chem 23(4):843-849

Tierney KB, Ross PS, Jarrard HE, Delaney KR, Kennedy CJ (2006) Changes in juvenile coho salmon electro-olfactogram during and after short-term exposure to current-use pesticides. Environ Toxicol Chem 25(10):2809-2817

Tierney KB, Singh CR, Ross PS, Kennedy CJ (2007a) Relation olfactory neurotoxicity to altered olfactory-mediated behaviors in rainbow trout exposed to three currently-used pesticides. Aquat Toxicol 81:55-64

Tierney KB, Ross PS, Kennedy CJ (2007b) Linuron and carbaryl differentially impair baseline amino acid and bile salt olfactory responses in three salmonids. Toxicology 231:175-187

Tierney KB, Baldwin DH, Hara TJ, Ross PS, Scholz NL, Kennedy CJ (2010) Olfactory toxicity in fishes. Aquat toxicol 96:2-26

Timmermann C, Gerhards R, Kubauch W (2003) The economic impact of site-specific weed control. Precis Agric 4:249-260 